\title{
The Resilience Of Deficit Thinking
}

\author{
Curt Dudley-Marling \\ Boston College
}

\begin{abstract}
Deficit thinking, which situates school failure in the minds, bodies, communities and culture of students, dominates schooling practices in the US and Canada. From this perspective, the remedy to school failure is to "fix" students, their families, culture or language. Critics of deficit thinking point to systemic factors, especially diminished opportunities to learn, to explain high levels of school failure among poor students and students of color. Decades of fierce critique have failed to diminish the appeal of deficit thinking. This paper considers the resistance of deficit thinking to critique by examining the appeal of Ruby Payne's Culture of Poverty, a particularly egregious instantiation of deficit thinking that pathologizes the language and culture of people living in poverty. The paper then turns to more recent work by the author to counter deficit thinking by showing what happens when students in highpoverty schools are challenged by the kind of thoughtful, engaging, high-expectation curricula common in affluent, high-achieving schools and classrooms.
\end{abstract}

\section{Introduction}

In the United States and Canada schooling is conceived as a competition with clear winners and losers. The winners go to the best colleges and universities with a pipeline to the highest status, most lucrative careers. The losers in this high-stakes contest are assigned to the lowest academic tracks, perhaps drop out, and, in the end, compete for low status, low paying jobs. This system of competitive schooling is generally deemed to be a fair way of allocating society's scarce resources since it is presumed that the people, who succeed, do the best in school and get the most desirable jobs, do so because they work the hardest and possess the most innate ability. It is similarly assumed that people who fail in school or the workplace do so because of a lack of ability and/or effort.

In this formulation, educational failure is seen as residing in the minds, bodies, culture and communities of individual students who "lack some critical attribute, ability, or potential" (Miller, 1993, p. 59). Students with learning disabilities, for example, are presumed to be lacking in requisite cognitive skills required for school success. A particularly pernicious version of deficit thinking situates the blame for high levels of educational failure among poor Black and Hispanic students, for example, in the cultural and linguistic practices of those groups. A highly influential study by Hart and Risley (1995), for instance, cites the putatively poor quality and quantity of linguistic interactions between children and their parents as the principal cause of high-levels of school failure among students living in poverty.

As readers of this journal are well aware, the belief that our current system of competitive schooling is fair has been the subject of vigorous critique. Critical educators argue that the structures of contemporary schooling tend to reinforce the status quo by privileging the cultural and linguistic experiences of children of the already privileged. Absent a "level playing field," critical educators argue, the current system of competitive schooling can never be fair.

A similarly forceful critique has been mounted against the deficit thinking that sustains the contemporary system of competitive schooling by situating school failure, and success, in the minds, bodies, communities and culture of students (see, Valencia, 1997). Critics of deficit thinking typically work from a social constructivist perspective which holds that learning failure does not reside in the minds of autonomous individuals as much as it dwells in activities and cultural practices situated in the context of human relations and institutions (Gergen, 1990). Lynda Miller (1993) puts it this way: "the traditional concept of self [as autonomous individual] has been challenged by a group of 
scholars who believe that the self resides not only inside the person, but also in the relationships, actions, artifacts, and objects surrounding her" (p. 63). This notion of a "distributed self" locates learning and learning failures in the "people, procedures, practices, events, and structures participating in and constituting the process we call 'education"' (Miller, 1993, p. 64). Put differently, no one can be a learning failure on her own. It takes a community of people doing just the right things in the right time and place for a student to fail in school (McDermott, 1993).

The practice of tracking offers a useful illustration of the contrast between deficit and social constructivist perspectives on learning failure. For deficit thinkers, the practice of tracking responds to differences in innate abilities that necessitate different pedagogical approaches and content for different groups of students. Presumably, segregating high and low achieving students allows teachers to challenge the most able learners without frustrating lower achievers who are assigned to lower academic tracks focused on their particular needs and abilities. From a social constructivist perspective, on the other hand, the practice of tracking influences students' success in school by creating qualitatively different affordances for learning for high and low achieving students. The circumscribed, low level, basic skills curriculum common in lower academic tracks, for example, more or less insures that low achieving students will fall further and further behind relative to their peers in higher academic tracks who are challenged with thoughtful, engaging curricula (Oakes, 2005, 2008). This same logic links the massive levels of school failure found among poor and minority students to the overrepresentation of these students in lower academic tracks (Oakes, 2008).

A half-century of critique has failed to diminish the power of deficit thinking (see DudleyMarling, 2007 for an historical overview of deficit thinking). Special and remedial education continues to focus on student deficiencies and educators and educational policy makers readily embrace deficit narratives to explain high levels of school failure among poor and minority students. A study I undertook with Pat Paugh (Dudley-Marling \& Paugh, 2010), based on Paugh's dissertation research, illustrates the resilience of deficit thinking. Over the course of an academic year we used readings, videos, and discussions to challenge three special education teachers working in urban schools to replace their deficit orientation toward students with disabilities with a social constructivist perspective. As the year progressed, the teachers demonstrated the ability to situate their discussions of students with disabilities in the discourse of social constructivism, but only when they considered students in the abstract. When they discussed specific examples of students with disabilities from their own classrooms they readily defaulted to the language of deficiencies.

In this paper, I consider the resistance of deficit thinking to critique by examining the appeal of a particularly egregious instantiation of deficit thinking, Ruby Payne's (2005) Culture of Poverty. Understanding the appeal of Ruby Payne offers insights into the allure of deficit thinking more generally. I then discuss my most recent, and, I believe, more effective, efforts to counter deficit thinking.

\section{Ruby Payne: A Framework For Understanding Poverty}

Ruby Payne is enormously popular across the United States and Canada. Her self-published book, $A$ Framework for Understanding Poverty (2005) has sold over one million copies (Valencia, 2010), making it, "perhaps, the single piece of literature most widely read by today's classroom teachers" (Ahlquist, Gorski, \& Montaño, 2011, p. 1). Payne's for-profit company, Aba! Process works with thousands of teachers each year with some districts paying hundreds of thousands of dollars for Payne to work with their teachers (Shapira, 2007). Payne's work has even found its way into practicum related university coursework (Smiley \& Helfenbein, 2011).

Payne's basic thesis is that there is a self-perpetuating "culture of poverty," based on what she calls "hidden rules," that prevents the poor from rising out of poverty (Payne, 2005). Hidden rules are "the unspoken cues and habits of a group" (p. 37) and Payne identifies a number of hidden rules that she argues are tied to economic class. According to Payne, people living in generational poverty view the "present as most important [and] decisions are made for the moment based on feelings or survival" (p. 42). For members of the middle class, on the other hand, the "future is most 
important [and] decisions are made against future ramifications" (p. 43). The "driving forces" for people living in poverty are "survival, relationships [and] entertainment" (p. 42) while "work [and] achievement" (p. 43) are the driving forces for the middle class. People living in poverty value education in the abstract "but not as reality" (p. 42). The middle-class, however, view education as "crucial for climbing the success ladder and making money" (p. 43).

Payne argues that learning the hidden rules is an adaptive skill, necessary for coping with the material circumstances of poverty, or wealth. Payne offers the example of a recently divorced woman who suddenly finds herself in situational poverty. To survive in her new circumstances, according to Payne, this woman "may need to use [her] body. Sex will bring money and favors. Values are important, but they don't put food on the table" (pp. 24-25). Crucially, the poor must learn the socalled hidden rules of the middle class if they are to climb out of poverty and achieve success in school and the workplace. Payne states: "For our students to be successful, we must . . . teach them the rules that will make them successful at school and at work" (p. 3).

One of Payne's central claims is that to help poor students move out of poverty and into the middle class, teachers must understand the nature of life in poverty. Toward this end, Payne (2005) describes a number of characteristics of poor people that typify the culture of poverty. As she tells it, people living in poverty move often; have common law marriages; know how to get guns; know "which grocery stores' garbage bins can be accessed for thrown-away food" (p. 38); and, know how to function at Laundromats. The poor view jail as an ordinary part of life. Their homes are disorganized, noisy, violent, and nonverbal. Men are often absent in poor families and single mothers engage in frequent, casual sex. Children and adults in poverty lack the verbal skills to resolve ordinary problems, succeed in school or even to comprehend a church sermon (Ehlig \& Payne, 1999). Payne uses various scenarios to illustrate the problems with which poor people must cope featuring children and adults whose chaotic lives are complicated by drugs, domestic and gang violence, sexual and physical abuse, prostitution, drunkenness, and teenage pregnancy. In general, Payne presents a pathological portrait of people living in poverty who lack the knowledge of (hidden) rules necessary for functioning normally in middle-class society.

Payne's "framework of understanding poverty" has been the subject of furious criticism by scholars who argue that Payne's work: instantiates deficit thinking that blames the poor for their material condition (e.g., Osei-Kofi, 2005; Valencia, 2010); pathologizes the poor by drawing on the basest stereotypes about people living in poverty (e.g., Bohn, 2007; Gorski, 2006); reinforces pernicious ethnic, racial, and gender stereotypes (e.g., Gorski, 2007; Montaño \& Quintanar-Sarrellana, 2011; Redeaux, 2011); lacks scientific evidence or scholarly merit, often misrepresenting the findings of social science researchers (e.g., Bomer, Dworin, May, \& Semingson, 2008; Ng \& Rury, 2006); and, reflects the thoroughly discredited theory that the poor share a common "culture of poverty" (e.g.; Ng \& Rury, 2006; Valencia, 2010).

Distressingly, there is little evidence that this extraordinarily negative portrayal of Ruby Payne's "culture of poverty" has diminished Payne's popularity. Despite the classist and racist undertones ${ }^{1}$, the base stereotypes, the outrageous claims (e.g., the poor typically eat food with their hands and not utensils [Payne \& Slocumb, 2010], teenage pregnancy is expected [Ehlig \& Payne, 1999]), and a complete absence of a research base, and she frequently misrepresents the research she does cite, Ruby Payne is "perhaps the most influential individual with shaping teacher practices for poor students in this country" (Cammarota, 2011, p. 251).

In the following section, I attempt to account for the appeal of Ruby Payne, and the relative powerlessness of critiques of her work, in the hope that this will provide some insight into the appeal of deficit perspectives more generally.

\section{The Appeal Of Ruby Payne}

According to narrative theorists, human understanding is constructed, organized and maintained through narratives (Freedman \& Combs, 1996; Schank, 1990). From this point of view, what Payne offers is a story, a particular narrative about the poor, how they live, why poor families are often 
stuck in a cycle of poverty, and how they can break out of poverty. Based on my reading of several of her books (e.g., Ehlig \& Payne, 1999; Payne, 2005; Payne \& Slocumb, 2010), Payne's narrative can be summarized using the following points:

- Poor children and their families are immersed in a pathological "culture of poverty," a situation largely of their own making;

- To escape the culture of poverty the poor need to learn the "hidden rules" of the middle class (put differently, they need to learn to be more like us);

- Escaping the culture of poverty requires the support of mentors/teachers who are members of the middle class;

- Learning the rules of the middle class, not handouts, will help the poor escape poverty;

- Some poor will not choose to learn the rules necessary to escape poverty; therefore, poverty is, at some level, a personal choice.

Examining the various elements of Payne's narrative about poverty helps to explain its appeal.

\section{The Poor Are the Problem}

Payne's narrative about people living in poverty positions the poor as the problem and, therefore, primarily to blame for their circumstances. The poor, Payne asserts, lack the verbal skills to solve problems and avoid violence or succeed in school. They engage in risky, sometimes criminal behavior, choose single-parent families, and prefer personal relationships to economic success. Therefore, if the poor wish to move into the mainstream of society, it is up to them to learn the rules needed for living and succeeding in middle-class society. Presenting poverty in terms of deficiencies in the minds, bodies, language and culture of the poor in this way implicates the poor for their circumstances and not the rest of us. We may feel sad about the effects of poverty on children and adults and we may choose to offer the help the poor need to "lift themselves" out of poverty. But it is not our problem and, more significantly, it is not our fault. An alternative, critical perspective situates the causes of poverty in the institutional structures in which each of us participates giving us all a share of the blame for poverty and its effects. No sophisticated analysis is required to explain the powerful appeal of a deficit model that blames them, and not us, over a complex, institutional analysis in which we all share some responsibility for poverty.

\section{The Poor Need to Be Saved}

Schank (1990) argues that people are likely to be attracted to narratives that match their own stories about the world. In her culture-of-poverty narrative, Payne makes it clear that to move into the middle class the poor need mentors/teachers who will rescue them by modeling and teaching them the "hidden rules" of the middle class (Payne, 2005; Ehlig \& Payne, 1999). The teacher-as-savior metaphor that is so prominently featured in Ruby Payne's story of poverty resonates strongly with portrayals of teachers in popular culture. Teachers as saviours of poor children of color, for example, is a familiar theme in teacher centered movies such as Dangerous Minds (Bruckheimer, Simpson, \& Smith, 1995) and Conrack (Ritt \& Bracht, 1974). Perhaps influenced by popular culture, many teachers come to urban schools fully embracing the teacher-as-saviour narrative (Galman, 2007). As Titone (1998) observes,

White educators, preservice as well as in-service, usually have good intentions for correcting the societal mistakes that exist in school settings. However . . . often they instinctively adopt, as one of their purposes for teaching, a messianic complex toward the children of oppressed groups. (p. 172)

The teacher-as-savior narrative is a highly problematic narrative that positions poor students of color as helpless victims "who lack the capacity to seek change" (Cammarota, 2011, p. 244) and, therefore, require the beneficence of white others to rescue them from their families, cultures, and communities 
(Michie, 2007). We have a moral responsibility to challenge pernicious, teacher-as-savior narratives. There is, however, an undeniable attraction to being the hero of our own narratives and even more appealing to being the hero of other people's narratives. Therefore, we should not be surprised that at least some teachers prefer Ruby Payne's portrayal of teachers of poor children as saviors or rescuers to our critical perspectives. Who wants to be told that they aren't heroes after all but, indeed, part of the problem?

\section{The Poor as People in Need of Saviors}

The power of the teacher-as-savior narrative depends on a companion narrative that portrays the poor as people in need of rescuing (Reyes \& Rios, 2003). This is where Ruby Payne may be most effective. Her books and presentations are chock full of anecdotes of violent and oversexed poor people, often poor people of colour, leading chaotic lives, unable to plan for a better future for themselves or their children. They are unable, or worse, unwilling, to sacrifice in the short term for long-term gains. More seriously the poor cannot offer their children the stable, rich, and stimulating educational environments middle-class parents routinely provide for their children. According to Ruby Payne, poor parents are unable, at least without the help of members of the middle class, to teach their children the hidden rules that are the key to escaping poverty. Instead, they must rely on the generosity of teachers/mentors who will rescue them from poverty. They need to be saved.

\section{Choosing a Life of Poverty: Hidden Rules, Not handouts}

In their book, What Every Church Member Should Know About Poverty, Ehlig and Payne (1999) share the following story.

In one school district, the faculty had gone together to buy a refrigerator for a [poor] family who did not have one. About three weeks later, the children in the family were gone for a week. When the students returned, the teachers asked where they had been. The answer was that the family had gone camping because they were so stressed. What had they used for money to go camping? Proceeds from the sale of the refrigerator, of course. (p. 24)

This story is meant to support Payne's claim that people in poverty are focused on entertainment and relationships rather than work and achievement as middle class families are. But this story makes the additional point about the futility of offering "handouts" to people in poverty who can't manage money or plan for the future. Learning the hidden rules of the middle class, not handouts, will enable the poor to move out of poverty and into the mainstream of the middle class. Payne asserts, however, that not all will choose to learn the hidden rules of the middle class. Some will choose poverty over a middle class life. To some degree, according to Payne, poverty is a matter of personal choice.

Ruby Payne's portrayal of the lives of people in poverty appeals to socially and fiscally conservative politicians and policy makers eager to cut programs for the poor in the service of reducing deficits. Moreover, like Payne, these people argue that social welfare programs breed dependency, not independence. If the poor wish to escape poverty they must learn the mainstream values of the middle class. Merely throwing money at the problem of poverty is, from this perspective, doomed to failure. If the poor choose poverty over prosperity, it is their choice and, therefore, not our problem. There is no need for us to feel guilty about the poor and, more importantly, no need to spend our money to 'cure' their problems.

As I have tried to show, Payne’s culture of poverty narrative has many appeals. But Payne's greatest appeal may lie in the simplicity of her argument. For Ruby Payne being poor is a function of personal failings and the solution to poverty is for the poor to pull themselves up by their bootstraps by learning the values, habits, and language of the middle class. This argument follows the reductionist logic of deficit thinking more generally. Contrast this straightforward deficit narrative 
with systemic analyses of poverty put forward by critical educators who cite a whole host of factors to account for poverty including poor nutrition and health, environmental toxins, violence, discrimination, hopelessness, structures of schooling that reproduce the status quo. Ask Ruby Payne or any other deficit thinker how to solve the problem of intergenerational poverty and they offer clear, straightforward solutions. Ask a critical educator the same question and they are likely to begin with the refrain: "It's complicated." I think this is right. The causes of and remedies for poverty are incredibly complex. But we must acknowledge that it is much more difficult to persuade people to accept a more complex narrative for poverty as opposed to a simple, and simplistic, narrative like Payne's. As Schank (1990) suggests, people are more willing to embrace simple narratives that they can readily understand and relate to other narratives that are already part of their worldview. Payne and other deficit thinkers offer that.

My brief analysis of Ruby Payne's "culture of poverty" leads me to conclude that deficit thinkers like Ruby Payne succeed because they offer a more compelling story than their critics. The complex narratives advanced by critical educators have generally failed to resonate with a significant number of teachers, administrators, policy makers and parents indicating the need for a different narrative. In the rest of this paper I discuss my recent efforts to compose a more persuasive alternative to deficit thinking.

\section{What Makes Children Smart?}

Lynda Miller (1993) has proposed a counter-narrative to the pernicious deficit thinking that underpins Ruby Payne's work based on a "philosophy of abundance." She states that;

The philosophy of abundance, in contrast to the philosophy of deficiency, is based on capability and competence. It presumes an optimistic explanation for human thinking, learning, and ability. This abundance perspective assumes that each person, regardless of age, gender, economic circumstance, or geographic location, is constantly in the process of constructing meanings based on her or his own life experiences. Further, this perspective allows us to see how we are curious and motivated to learn given appropriate circumstances. (p. 57)

An abundance narrative presumes that all children are smart, that every child comes to school with rich cultural and linguistic experiences, complex language practices, and innate intelligence. This stance takes for granted that nearly all children, including poor children, have loving parents who care deeply for them and their futures even if not all families possess the same levels of economic and cultural capital to support their children. Responding to claims that poor, Black students spoke an inferior variety of English, for example, William Labov (1972) provided clear evidence that socalled Black Vernacular English is as rich and rule-governed as any other variety of the English language. Other researchers have also emphasized the linguistic abundance of poor and minority children (e.g., Michaels, 1981).

This shift in focus from deficiencies to abundance has important consequences for educators and others. Working from an abundance narrative leads, for example, to an entirely different set of questions when children experience school troubles. Instead of asking, "What's wrong with this child?" an abundance narrative leads to questions like such as, "What's gone wrong here?" "How did school fail this child?" Working from a philosophy of abundance, James Gee (2004) asks,

What is it about school that manages to transform children who are good at learning . . regardless of their economic and cultural differences, into children who are not good at learning, if they are poor or members of certain minority groups? (p. 10) 
From this perspective, the child isn't the problem. Nor is the child's family, community or culture the problem. Instead, understanding that "the problem is the problem" (Freedman \& Combs, 1996, p. 47) helps lead educators to focus on expanding students' affordances for learning, instead of trying to fix children, their families or culture.

Confronting the deficit narrative in Payne's "culture of poverty" and deficit discourses of schooling more generally demands that people not just learn a new narrative but unlearn old deficit narratives. Schank (1990) argues that, "We can learn from the stories of others, but only if what we hear relates strongly to something we already knew ... But mostly we learn from a reexamination of our own stories" (p. 83). Earlier in this paper I described for readers our less-than-successful efforts to shift the thinking of three special education teachers about the nature of their students' disabilities. Recall that these three special education teachers were able to articulate a social constructivist stance on disability in the abstract but when discussing their own students they quickly reverted to the language of deficit thinking. They learned a perspective that situated disabilities outside the minds and bodies of students but they didn't unlearn the deficit thinking that undergirded their day-to-day work with students with disabilities. Deficit thinking has achieved the status of common sense, instantiated in language rich with possibilities for situating learning failures in students' bodies (e.g., handicapped, reading disabled, struggling reader, deprived, mentally retarded). Conversations about school failure inevitably begin with the question, "what is wrong with this child?". The dominance of deficit thinking in American and Canadian culture is a major factor in the appeal of Ruby Payne. Most people already believe that poverty is a function of personal failings. Payne is just filling in the particulars by appealing to already-held stereotypes about poverty and the poor. In the following sections I share my recent efforts to create an alternative to deficit thinking that helps teachers learn a narrative of abundance while challenging them to unlearn the deficit narrative that dominates contemporary discourses of schooling.

\section{High Expectation Curricula: The Case Of Interpretive Discussion}

Concomitant with deficit thinking is low-level, basic skills curricula aimed at remediating students' deficiencies (Oakes, 2005). This is the most serious consequence of deficit thinking: it leads to instructional practices that diminish student learning by limiting students' access to the rich learning opportunities routinely afforded to students in affluent, high-achieving schools and classrooms. Students targeted by these practices learn less and learn more slowly because of the scope and pace of the remedial curricula to which they are subjected.

The antidote to the disabling, deficit-based "pedagogy of poverty" (Haberman, 1991, p. 290) is to provide students in high poverty schools with the sort of high-expectation curriculum typically reserved for students in high-achieving classrooms. The Optimum Learning Environment (OLE) project, for example, brings rich, engaging curriculum typically found in classes for gifted students to inner city, ELL special education classrooms with great success (Ruiz \& Figueroa, 1995). Similarly, "Poetry Inside Out" (Rutherford, 2012) uses translation of masterworks to engage students from diverse linguistic and cultural backgrounds in reading and writing poetry. At a more structural level, an accumulating body of research has documented the positive effects of de-tracking as a means of bringing engaging, high-level learning to high- and low-achieving students (e.g., Oakes, 2005, 2008; Watanabe, 2008).

Research and professional development I have done with urban teachers on the practice of Interpretive Discussion (Haroutunian-Gordon, 2009) offers a further illustration of the power of highexpectation curricula to engage students in high poverty schools in challenging, high-level learning. This work offers clear evidence of the ability of students in high poverty schools to engage in highlevel literacy learning while modeling for teachers one example of a high-expectation curricular practice. The goal of Interpretive Discussion is to engage students in the practice of evidence-based discussions of challenging texts organized around broad questions posed by teachers, for which there is textual evidence. Teachers manage discussions by requiring that students cite evidence to support their responses and, if deemed necessary, to cite the evidentiary warrant for their claims. Students are 
encouraged to respectfully agree and disagree. The key to these discussions, however, is the focus of evidence-based reasoning rather than students competing for the right answer. Toward this end, teachers pose questions for which there is more than one possible answer and during discussions refrain from any evaluation of students' responses.

\section{Interpretive Discussion in a $4^{\text {th }}$ Grade Classroom}

The following excerpt comes from a discussion of a story called "Cedric" (Jansson, 1962) in a fourth grade classroom in a low-achieving, high-poverty school in the South Bronx. It will help readers interpret the discussion if they have a sense of the story so I provide a brief summary here.

"Cedric" is about a boy named Sniff who has a stuffed animal named Cedric who has topaz eyes and a moonstone on his collar. The text says, "Possibly the moonstones were more important to Sniff than the dog's inimitable expressions." Sniff gives Cedric away but immediately regrets the decision. Sniff visits Sniffkin who tells him a story about a woman who had beautiful things that she collected and took care of, to the exclusion of friends or travel. She gets a bone stuck in her stomach and thinks she has only a few weeks to live. She has the idea to give all her stuff away (because she's suffocating), sending just the right thing to different people in anonymous parcels. She starts to feel better, gets nicer, friends start to visit, and one day she laughs so hard that the bone comes out. She's changed and goes off to travel the world. Eventually, Sniff finds Cedric but the topaz eyes have been removed and made into eardrops and the moonstone on the collar has been lost. But, as the story says, Sniff loves Cedric "all the same," but now "only for love's sake."

Consider the following exchange, part of a 54 minute discussion as the fourth-grade students responded to the teacher's framing question, "Why at the end does Sniff love Cedric 'only for love's sake?"”

Megan: I think that Sniff only at the end loves Cedric for love's sake because now that he, he have no moonstone, so, like . . . Cedric, he thought that he should love him for who he was, now that he don't have the moonstone.

[Derrick immediately attempts to reframe the question]

Derrick: I have a question for you (to Megan). Would he still love him if he still had the moonstone?

Megan: Yeah, of course.

Derrick: So then why did you say that he loves him now that he didn't have the moonstone? And did that make any difference?

[Pause]

Teacher: Clarify your question. She doesn't understand your question.

Derrick: It doesn't make any difference whether he has the moonstone, or not. He still loved Cedric.

Megan: It said in the story that he loved him for the moonstone.

Teacher: Where did it say that?

Megan: (Looks at page) Let me see.

Teacher: Hold on. Do you need help Megan? (Megan nods) O.K. Go ahead, tell her, Jackie. Where? 
JOURNAL OF TEACHING AND LEARNING, 2015, VOL.10, NO. 1

Jackie: In page $80 \ldots$ it says, the first paragraph, it says, "An expression that no other dog could ever have. Possibly the jewels were more important to Sniff than the expressions."

\section{Teacher: So Derrick?}

Derrick: So then he wouldn't love Cedric if it was because of the moonstone, would he?

Jason: But he loves Cedric. He say's he loves Cedric for love's sake.

Derrick:I know but what she's saying, it's because of the moonstone.

Jasmine: At the end he realized that it doesn't matter if he don't have ... jewelry on.

Teacher: How did he realize that? What makes you think he realized it?

Jackie: (looks in book) I think that he realized that because he found him inside the rain, when he found him inside the rain, and ... and he didn't have no jewelry on [Teacher: uh huh] and it says that he loved him all the same, that he loved him the same way he loved him with the jewelry on.

Teacher: Diarra, what do you have to add to that?

Diarra: I understand what Jasmine was saying, that um, that he ended up loving him in the end because the time ... he found him, he finally he realized how much he really love Cedric, even, even, even though he, in the beginning, he lacked, he lacked so many jewels.

Derrick: So let me get this straight. You're saying that she loves him with or without the jewelry? I

mean he loves, he loves Cedric with or without the jewelry?

Jason: Yes, he does.

Derrick: Then why would Diarra say that she loved him, I mean he loved Cedric because of the moonstones?

Jason: Alright. She said for both, even without it. She says he loves him with the moonstones and without the moonstones.

In this brief excerpt, typical of the discussions I have observed in this and other urban classrooms using Interpretive Discussions, the students do the bulk of the talking, taking more and longer turns than their teacher, a complete reversal of the usual pattern of student-teacher talk in elementary classrooms (Cazden, 2001). More significantly, these fourth-grade students made claims, cited evidence, and respectfully challenged and supported one another as they collaboratively made sense of a complex, challenging text. Looking past the dialect speech and occasional dys-fluencies it is clear that these students engaged in the high-level reasoning and engagement associated with affluent, high-achieving students. Indeed, the general shape of this discussion resembles the interactions common in my graduate classes at Boston College.

Interpretive Discussion, a demanding, high-expectation curricular practice, created affordances for learning that enabled a group of students in a high-poverty school in the South Bronx, many of whom had been identified as ELL or as having special needs, to show that they are smart, capable and thoughtful people. This is the essence of my recent work to counter Ruby Payne and other deficit mongers. Rather than TELLING teachers about the negative consequence of 
deficit thinking, or merely describing pedagogical alternatives to deficit-based curricula in the abstract, I have been sharing video recordings of discussions like the one in the South Bronx to show what happens when low-achieving students in high poverty schools are challenged with high-expectation curricula. Crucially, the students in the South Bronx video and other videos I have been sharing with urban teachers "look like" their students. Videos of discussions featuring children in suburban classrooms are never persuasive. When possible I also model discussions in teachers' classrooms showing them what their students can do when challenged with a high-expectation curricular practice like Interpretive Discussion. Arguably, this is the most powerful demonstration of all.

Data from research on Interpretive Discussion and other high-expectation practices resonate with one of the most powerful narratives animating contemporary educational reform: it works. Evidence from research on the efficacy of various high-expectation curricula indicates students' ability to engage in high-level learning that positively affects student achievement. The South Bronx school from which the above discussion came experienced large gains on state and district literacy assessments after implemented Interpretive Discussions in their K-4 classrooms. Indeed, there is a body of evidence indicating that academically rigorous discussions positively affect academic performance in language arts (Lee, 2001); mathematics (Chapin, O'Connor, \& Anderson, 2003; Lampert \& Ball, 1998); high school physics (Minstrell, 1989); and, elementary (Warren \& Rosebery, 1996) and middle-school science classrooms (Sohmer, 2000; see also, Dudley-Marling \& Michaels, 2012 for a collection of essays documenting the efficacy of high-expectation curricula).

My recent experience working with urban teachers indicates that, faced with evidence that shows poor students' ability to engage in rich, thoughtful learning, teachers in high-poverty schools are willing and able to unlearn deficit thinking and replace it with a philosophy of abundance. And, as these teachers begin to engage their students in higher levels of learning they generate their own stories of abundance.

\section{Conclusion}

Showing what happens when students in high-poverty schools are challenged by high-expectation curricula exposes the lie of Ruby Payne's narrative of deficiency and deficit thinking more generally. Children living in poverty are not lacking in language or cognition. They are deficient, however, in opportunities for thoughtful, engaging learning. High-expectation curricula like Interpretive Discussions offer an antidote to the stultifying, low-level, basic skills curriculum common in high poverty schools and classrooms. I recognize, however, that a high-expectation curriculum founded on a narrative of abundance will be insufficient for overcoming the material effects of poverty. The richest curricular practices must be augmented by policies and practices that address the conditions of poverty that will always limit the possibilities of poor children.

Finally, despite my positive experiences confronting narratives of deficiency with evidence that children in poverty, like all children, are inherently smart, confronting the narrative of deficit thinking will always be a challenge. Implicating curricular practices - and the conditions of poverty more generally - as the chief factors in high levels of school failure among children living in poverty conflicts with deeply held cultural stories about individual agency that undergird deficit thinking. Moreover, a systemic analysis of poverty suggests a complex narrative that resists easily solutions. A philosophy of abundance does not offer silver bullet solutions to the problem of poverty. Deficit thinkers like Ruby Payne, on the other hand, offer a relatively simple remedy to the problem of poverty: the promise to solve the problem of poverty by fixing poor children and their families. And, if the poor continue to fail, well, it's their choice.

A narrative of abundance will also encounter resistance from entrenched political and economic interests that benefit from deficit narratives of poverty. A philosophy of abundance threatens conservative narratives of rugged individualism as well as corporate interests that reap enormous profits from practices like Direct Instruction that offer a pedagogical "fix" for children in poverty (see, for example, Dudley-Marling \& Paugh, 2005). Despite these obstacles, I believe that it will be much more difficult to sustain a narrative of deficiency in the face of a narrative that 
illustrates the abundance of cognitive and linguistic skill that all children possess. The key is to show and not tell. We need stories that show what students can do given the opportunities typically afforded more affluent students and not rely on telling complex stories based on systemic analyses of poverty. Simply put, to counter deficit thinking we need a more persuasive narrative.

\section{Endnotes}

1. Payne herself dismisses claims of racism in her writing but, as Bomer, Dworin, May and Semingson (2008) observe, her anecdotes about the poor routinely feature Black people even though the majority of poor in the United States are white (US Census Bureau, 2012).

\section{References}

Ahlquist, R., Gorski, P., \& Montaño, T. (2011). Introduction. In P. Gorski, T. Montaño, \& R. Ahlquist (Eds.), Assault on kids (pp. 1-8). New York: Peter Lang.

Bohn, A. (2007). A framework for understanding Ruby Payne. Rethinking Schools, 21(2), 13-15.

Bomer, R., Dworin, J., May, L., \& Semingson, P. (2008). Miseducating teachers about the poor: A critical analysis of Ruby Payne's claims about poverty. Teachers College Record, 110(12), 2497-2531.

Bruckheimer, J. (Producer), Simpson, D. (Producer), \& Smith, J.N. (Director). Dangerous Minds (Motion picture). United States: Hollywood Pictures.

Cammarota, J. (2011). Blindsided by the avatar: White saviors and allies out of Hollywood and in education. Review of Education, Pedagogy, and Cultural Studies, 33, 242-259.

Chapin, S., O'Connor, C., \& Anderson, N. (2003). Classroom discussions: Using math talk to help students learn: Grades 1-6. Sausalito, CA: Math Solutions Publications.

Cazden, C. (2001). Classroom discourse: The language of teaching and learning. Portsmouth, NH: Heinemann.

Dudley-Marling, C. (2007). Return of the deficit. Journal of Educational Controversy: An Interdisciplinary Journal of Ideas, 2(1), article 5. Available at cedar.wwu.edu.

Dudley-Marling, C., \& Michaels, S. (Eds.) (2012). High-expectation curricula: Helping all students succeed with powerful learning. New York: Teachers College Press.

Dudley-Marling, C., \& Paugh, P. (2010). Confronting the discourse of deficiencies. Disability Studies Quarterly, 30(2). Available at dsq-sds.org.

Dudley-Marling, C., \& Paugh, P. (2005). The rich get richer, the poor get Direct Instruction. In B. Altwerger (Ed.), Reading for profit: How the bottom line leaves kids behind (pp. 156-171). Portsmouth, NH: Heinemann.

Ehlig, B., \& Payne, R. K. (1999). What every church member should know about poverty. Highlands, TX: Aha! Process.

Freedman, J., \& Combs, G. (1996). Narrative therapy: The social construction of preferred realities. New York: Norton.

Galman, S. A. C. (2007). The life you save be your own: White, female pre-service teachers imagine the marginalized student. Journal of Border Educational Research, 6(2), 7-17.

Gee, J. P. (2004). Situated language and learning: A critique of traditional schooling. New York: Routledge.

Gergen, K. J. (1990). Social understanding and the inscription of self. In J.W. Sigler, R. A. Shweder, \& G. Herdt (Eds.), Cultural psychology: Essays on comparative human development (pp. 569-606). New York: Cambridge University Press.

Gorski, P. (2006). The classist underpinnings of Ruby Payne's framework. Teachers College Record. Available at http:///www. tcrecord.org.

Gorski, P. (2007). Savage unrealities: Classism and racism abound in Ruby Payne's framework. Rethinking Schools, 21(2), 16-19.

Haberman, M. (1991). The pedagogy of poverty versus good teaching. Phi Delta Kappan, 73(4), 290-294.

Haroutunian-Gordon, S. (2009). Learning to teach through discussion: The art of turning the soul. New Haven, CT: Yale University Press.

Hart, B., \& Risley, T. R. (1995). Meaningful differences in the everyday experiences of young American children. Baltimore, MD: Brookes.

Jansson, T. (1962). “Cedric.” In Tales from Moominvalley (T. Warburton, Trans.), by T. Jansson, (pp.150-161). New York: Farrar, Strauss, Giroux.

Labov, W. (1972). The language of the inner city. Philadelphia, PA: University of Pennsylvania Press.

Lampert, M., \& Ball, D. (1998) Teaching, multimedia, and mathematics: Investigations of real practice. New York: Teachers College Press. 
Lee, C. (2001). Is October Brown Chinese? A cultural modeling activity system for underachieving students. American Educational Research Journal, 38(1), 97-141.

McDermott, R. P. (1993). The acquisition of a child by a learning disability. In C. Chaiklin \& J. Lave (Eds.), Understanding practice: Perspectives on activity and context (pp. 269-305). New York: Cambridge University Press.

Michaels, S. (1981). Sharing time: Children's narrative styles and differential access to literacy. Language in Society, $10(3), 423-442$.

Michie, G. (2007). Seeing, hearing and talking race: Lessons for white teachers from four teachers of color. Multicultural Perspectives, 9(1), 3-9.

Miller, L. (1993). What we call smart: A new narrative for intelligence and learning. San Diego: Singular Publishing Group.

Minstrell, J. (1989). Teaching science for understanding. In L.B. Resnick \& L.E. Lopfer (Eds.), Toward the thinking curriculum: Current cognitive research (1989 Yearbook of the Association for Supervision and Curriculum development), (pp: 131-149). Alexandria, VA: Association for Supervision and Curriculum Development.

Montaño, T., \& Quintanar-Sarellana, R. (2011). Undoing Ruby Payne and other deficit views of English language learners. In R. Ahlquist, P., Gorski \& T. Montaño (Eds.), Assault on kids: How hyper-accountability, corporatization, deficit ideologies, and Ruby Payne are destroying our schools (pp. 199-213). New York: Peter Lang.

Ng, J. C., \& Rury, J. L. (2006). Poverty and education: A critical analysis of the Ruby Payne phenomenon. Teachers College Record. Available at http://:www.tcrecord.org.

Oakes, J. (2005). Keeping track: How schools structure inequality. New Haven, CT: Yale University Press.

Oakes, J. (2008). Keeping track: Structuring equality and inequality in an era of accountability. Teachers College Record, 110 (3), 700-712.

Osei-Kofi, N. (2005). Pathologizing the poor: A framework for understanding Ruby Payne's work. Equity and Excellence in Education, 38(4), 367-375.

Payne, R. K. (2005). A framework for understanding poverty ( $4^{\text {th }}$ ed.). Highlands, TX: Aha! Process, Inc.

Payne, R. K., \& Slocumb, P. D. (2010). Boys in poverty: A framework for understanding dropout. Bloomington, IN: Solution Tree.

Redeaux, M. (2011). A framework for White privilege: A critique of Ruby Payne. In R. Ahlquist, P.C. Gorski \& T. Montaño (Eds.), Assault on kids: How hyper-accountabity, corporatization, deficit ideologies, and Ruby Payne are destroying our schools (pp. 177--98). New York: Peter Lang.

Reyes, X. A., \& Rios, D.I. (2003). Imaging teachers: In fact and in the mass media. Journal of Latinos and Education, 2(1), 3-11.

Ritt, M. (Producer) \& Bracht, F. (Director) (1974). Conrack (Motion picture). United States: $20^{\text {th }}$ Century Fox.

Ruiz, N., \& Figueroa, R. (1995). Learning-handicapped classrooms with Latino students: The optimal learning environment (OLE) project, Education and Urban Society, 27(4), 463-483.

Rutherford, M. (2012). Poetry Inside Out: A high-expectation, cross-cultural literacy program. In C. Dudley-Marling \& S. Michaels (Eds.), High-expectation curricula: Helping all students succeed with powerful learning (pp. 4558). New York: Teachers College Press.

Schank, R. C. (1990). Tell me a story: Narrative and intelligence. Evanton, IL: Northwestern University Press.

Shapira, I. (2007). Author's poverty views disputed yet utilized: Materials have guided Va., Md. Teachers. Washington Post, A01.

Smiley, A. D., \& Helfenbein, R. J. (2011). Becoming teachers: The Payne effect. Multicultural Perspectives, 13(1), 515.

Sohmer, R. (2000). 'A Page So Big No One Can Fall Off': Apprenticeship as the architecture of intersubjectivity in an after-school science program for inner city middle school students. (Unpublished Dissertation, Clark University).

Titone, C. (1998). Educating the white teacher as ally. In J. L. Kinchloe, S.R. Steinberg, N.M. Rodriguez, \& R.E. Chennault (Eds.), White reign: Deploying whiteness in America (pp. 159-175). New York: St. Martin's Press.

US Census Bureau (2012). Poverty. Retrieved August 26, 2012 from http://www.census.gov/hhes/www/poverty/poverty.html

Valencia, R. R. (2010). Dismantling contemporary deficit thinking: Educational thought and practice. New York: Routledge.

Valencia, R. R. (1997). The evolution of deficit thinking: Educational thought and practice. New York: RoutledgeFalmer.

Warren, B., \& Rosebery, A. (1996). 'This question is just too, too easy': Perspectives from the classroom on accountability in science. In L. Schauble \& R. Glasser (Eds.), Innovations in Learning: New Environments for Education (pp: 97-125). Hillsdale, NJ: Earlbaum.

Watanabe, M. (2008). Tracking in the era of high stakes state accountability reform: Case studies of classroom instruction in North Carolina. Teachers College Record, 110 (3), 489-534. 